\title{
Color Change in Fresh Red Raspberry Fruit Stored at 0, 4.5, or $20 \mathrm{C}$
}

\author{
Jo Ann Robbins ${ }^{1}$ and Patrick P. Moore ${ }^{2}$ \\ Washington State University Puyallup Research and Extension Center, \\ Puyallup, WA 983714998
}

Additional index words. Rubus idaeus, postharvest, anthocyanin, color coordinates

\begin{abstract}
During storage for 16 days at 0 or $4.5 \mathrm{C}$ or storage for 8 days at $20 \mathrm{C}$, fresh raspberry (Rubus idaeus L. var. idaeus) fruit became darker, less red, and more blue as recorded in $L^{*} a^{*} b^{*}$ CIE coordinates. Cultivars maintained their relative at-harvest ratings throughout storage. Rates of change for cultivars during storage did not differ. Color changes depended on temperature, with rates of change fastest at $20 \mathrm{C}$, especially during the first 4 days. Fruit stored 16 days at $\mathrm{OC}$ was more red and less blue than that stored at $4.5 \mathrm{C}$. Maximum color change was reached after 8 days at 0 or $4.5 \mathrm{C}$ and after 4 days at $20 \mathrm{C}$.
\end{abstract}

Fresh fruit of red raspberry changes color during storage as anthocyanins develop and $\mathrm{pH}$ increases (Robbins and Sjulin, 1989; Sjulin and Robbins, 1987; Varseveld and Richardson, 1980). Munsell value (light/dark) scores in 'Meeker' fruit decreased (darkened) during storage and value scores were correlated with anthocyanin concentration (Sjulin and Robbins, 1987). This color change is a characteristic that detracts from good postharvest appearance. Fruit color after storage depends on cultivar (Sjulin and Robbins, 1983) and storage temperature (Varseveld and Richardson, 1980). We report here a quantitative investigation of temporal color change in four cultivars of red raspberry and its relationship to storage temperature.

Fruit was harvested on 6 July 1988 from four-hill plots sprayed with Ronilan (2.4 g.liter ${ }^{-1}$ ) on 6 and 13 June and thereafter weekly with Captan (2.4 g.liter $\left.{ }^{-1}\right)$ to control postharvest rot due to Botrytis cinerea Pers. ex. Fr. Choice of cultivars was based on previous knowledge of color change after storage: 'Chilcotin' is light red, 'Meeker' is a medium red, while 'Nootka' and 'Willamette' are dark (Robbins and Sjulin, 1989; Sjulin and Robbins, 1983). Fruit were harvested at the red-ripe stage of maturity (Sjulin and Robbins, 1987) into Styrofoam egg cartons, one fruit per compartment, with three replications (cartons) for each temperature/ storage period combination.

Fruit were placed into storage at 0 or $4.5 \mathrm{C}$, for 0 (at harvest), 4, 8, 12, or 16 days or at 20C for 0 (at harvest), 2, 4, 6, or 8 days.

Received for publication 12 Mar. 1990. H/LA Paper no. 89-36. Washington State Univ., College of Agriculture and Home Economics, Pullman, Wash. Project no. 0640. Partially supported by a grant from the Washington Red Raspberry Commission. The cost of publishing this paper was defrayed in part by the payment of page charges. Under postal regulations, this paper therefore must be hereby marked advertisement solely IO indicate this fact.

${ }^{1}$ Horticulture Research Specialist.

${ }^{2}$ Assistant Horticulturist.
Fruit was in the controlled conditions within $4 \mathrm{hr}$ after harvest. Each sample day, fruit were placed at 20C for $4 \mathrm{hr}$ before measurement. Color was measured on the first five sound, nonmoldy fruit from each carton. The mean of the five fruit measurements was used for data analysis.

Color was measured on the side of a slightly flattened whole fruit using a tristimulus color analyzer (Chroma Meter, Model CR-200b, Minolta, Ramsey, N.J.) equipped with a measuring head with an 8-mm-diameter measuring area. The analyzer was calibrated to a standard white reflective plate and used CIE (Commission Internationate d l'Eclairage) Illuminant $C$. Measurements were recorded in $\mathrm{L}^{*} \mathrm{a}^{*} \mathrm{~b}^{*}$ CIE coordinates. The $\mathrm{L}^{*}$ scale ranges from no reflection $\left(\mathrm{L}^{*}=0\right.$, black) to perfect diffuse reflection $\left(\mathrm{L}^{*}=\right.$ 100 , white); the $\mathrm{a}^{*}$ scale ranges from negative values for green to positive values for red, and the $b^{*}$ scale ranges from negative values for blue to positive values for yellow.

The five fruit from one replication were frozen at $-20 \mathrm{C}$ as a single sample after measurements had been taken. Total anthocyanins were determined spectrophotometrically from acidified ethanol extracts from the frozen samples (Torre and Barritt, 1977) and expressed as milligrams of cyanidin 3galactoside per gram of fruit.

$L^{*} a^{*} b^{*}$ values for a single replication were plotted against the anthocyanin concentration (data not shown). Previous work with very dark pigments had found an "area of confusion" using $L^{*} a^{*} b^{*}$ scales where, at a certain point, as pigment concentration increased, changes in scale readings did not increase or decrease in a corresponding manner (Eagerman et al., 1973a). Mathematical conversion to L' a' b' values was recommended (Eagerman et al., 1973b) to produce a better correlation of pigment Concentration to color scale values. Correlation coefficients for our data showed that conversion did not improve the relationship enough to warrant conversion ( $r$ for $\mathrm{L}^{*}, \mathrm{a}^{*}, \mathrm{~b}^{*}, \mathrm{~L}$, , a', and $b^{\prime}$ with anthocyanin concentration $=$
$-0.73,-0.80,-0.79,-0.73,-0.78$, and -0.80 , respectively). Even the darkest samples were below any pigment concentration that might produce an area of confusion.

$\mathrm{L}^{*}, \mathrm{a}^{*}$, and $\mathrm{b}^{*}$ values all decreased with increasing storage time with the linear and quadratic component being significant (Tables 1 and 2). During storage, fruit became darker, less red, and more blue.

Cultivars maintained their relative at-harvest rating in $L^{*}, a^{*}$, and $b^{*}$ values throughout storage (Tables 1 and 2). 'Chilcotin' was more red and less blue than any other cultivar. 'Meeker' was lighter, more red, and less blue than any other cultivar except 'Chilcotin'. 'Nootka' and 'Chilcotin' had similar L* values, but 'Nootka' was both less red and more blue than 'Chilcotin' and 'Meeker'. 'Willamette' was darker, less red, and more blue than any other cultivar at 0 and 4.5C (Table 1). At 20C, however, 'Nootka' was equal to 'Willamette' in $\mathrm{a}^{*}$ and $b^{*}$ values (Table 2).

The $\mathrm{a}^{*}$ and $\mathrm{b}^{*}$ values were higher at 0 than at $4.5 \mathrm{C}$ during storage up to 16 days (Table 1). Fruit was less red and more blue at $4.5 \mathrm{C}$. There was no difference in $\mathrm{L}^{*}$ values at the two temperatures. Also, overall values of $\mathrm{L}^{*}$, $\mathrm{a}^{*}$, and $\mathrm{b}^{*}$ did not change after 8 days at 0 or $4.5 \mathrm{C}$ (Table 1). Fruit stored at $20 \mathrm{C}$ darkened, became less red and more blue through

Table 1. Effect of storage temperature and duration of storage on fruit color of four cultivars of red raspberry.

\begin{tabular}{lllr}
\hline \hline & \multicolumn{3}{c}{$\begin{array}{c}\text { Color } \\
\text { coordinate value }\end{array}$} \\
\cline { 2 - 4 } Variable & \multicolumn{2}{c}{$\mathrm{a}^{*}$} & $\mathrm{~b}^{*}$ \\
\hline Cultivar [C] & & & \\
Chilcotin & $29.3 \mathrm{~b}^{2}$ & $26.5 \mathrm{a}$ & $10.7 \mathrm{a}$ \\
Mecker & $29.8 \mathrm{a}$ & $23.9 \mathrm{~b}$ & $9.5 \mathrm{~b}$ \\
Nootka & $29.1 \mathrm{~b}$ & $21.4 \mathrm{c}$ & $7.8 \mathrm{c}$ \\
Willamette & $28.0 \mathrm{c}$ & $19.3 \mathrm{~d}$ & $7.2 \mathrm{~d}$ \\
Storage tempcraturc & & & \\
( ${ }^{\circ} \mathrm{C}$ ) (T) & & & \\
0 & 29.2 & 23.2 & 9.1 \\
4.5 & 28.9 & 22.4 & 8.5 \\
Sioragc duration & & & \\
(days) [S] & & & \\
0 & 30.3 & 25.8 & 11.1 \\
4 & 29.4 & 23.4 & 9.1 \\
8 & 28.8 & 22.0 & 8.3 \\
12 & 28.3 & 21.0 & 7.6 \\
10 & 28.4 & 21.7 & 7.9
\end{tabular}

Significance of the

F ratio

from analysis

of variance

C

T

$\mathrm{S}$

S lincar

$S$ quadratic

$S$ cubic

$S$ residual

$\mathrm{C} \times \mathrm{T}$

$\mathrm{C} \times \mathrm{S}$

$T \times S$

$\mathrm{C} \times \mathrm{T} \times \mathrm{S}$

\begin{tabular}{lll}
$*$ & $\cdots$ & $\cdots$ \\
$N S$ & $\cdots$ & $*$ \\
$\cdots$ & $\cdots$ & $*$ \\
NS & NS & $\cdots$ \\
NS & NS & NS \\
NS & NS & NS \\
NS & NS & NS \\
$*$ & NS & NS \\
NS & NS & NS \\
\hline
\end{tabular}

${ }^{\mathrm{z}}$ Mean separation by Duncan's multiple range test, $P=0.05$.

Ns $* * *$ Nonsignificant or significant at $P=0.05$ or 0.01 , respectively. 
Table 2. Effect of duration of storage at $20 \mathrm{C}$ on

\begin{tabular}{|c|c|c|c|}
\hline \multirow[b]{2}{*}{ Variable } & \multicolumn{3}{|c|}{$\begin{array}{c}\text { Color } \\
\text { coordinatc value }\end{array}$} \\
\hline & $L^{*}$ & $a^{*}$ & $b^{*}$ \\
\hline \multicolumn{4}{|l|}{ Cultivar $[\mathrm{C}]$} \\
\hline Chilcotin & $28.6 b^{\prime}$ & $25.2 \mathrm{a}$ & 10.0 \\
\hline Mccker & $29.5 \mathrm{a}$ & $22.3 \mathrm{~b}$ & 8.2 \\
\hline Nootka & $28.6 \mathrm{~b}$ & $18.8 \mathrm{c}$ & 6.7 \\
\hline Willamctte & $27.6 \mathrm{c}$ & $17.9 \mathrm{c}$ & 6.5 \\
\hline \multicolumn{4}{|l|}{$\begin{array}{l}\text { Storage duration } \\
\text { (days) [S] }\end{array}$} \\
\hline 0 & 30.6 & 26.2 & 11.3 \\
\hline 2 & 28.6 & 22.0 & 8.3 \\
\hline 4 & 27.8 & 19.6 & 6.9 \\
\hline 6 & 28.5 & 18.5 & 6.5 \\
\hline 8 & 27.4 & 18.9 & 6.2 \\
\hline \multirow{2}{*}{\multicolumn{4}{|c|}{$\begin{array}{l}\text { Significance of the } \\
\text { F ratio } \\
\text { from analysis } \\
\text { of variance }\end{array}$}} \\
\hline & & & \\
\hline C & ** & $\cdots$ & ** \\
\hline $\mathrm{S}$ & $* *$ & $\cdots$ & $\cdots$ \\
\hline S lincar & ** & $\cdots$ & ** \\
\hline$S$ quadratic & $*$ & 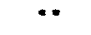 & $\cdots$ \\
\hline$S$ icsidual & is & NS & NS \\
\hline$C \times S$ & VS & vS & NS \\
\hline
\end{tabular}

${ }^{\mathrm{z}}$ Mean scparation by Duncan's multiple range test. $P=0.05$.

NS, $* *$ Nonsignificant or significant at $P=0.01$.

4 days of storage and with longer storage, values of $\mathrm{L}^{*}, \mathrm{a}^{*}$, and $\mathrm{b}^{*}$ did not change (Table 7). $\mathrm{L}^{*}, \mathrm{a}^{*}$, and $\mathrm{b}^{*}$ values at $0 \mathrm{C}$ at 8 days (Table 1) and at 20C at 4 days (Table 2) were similar, indicating that maximum color change had been reached. The significant quadratic component of storage time confirmed this conclusion. A significant cubic effect was evident for $b^{*}$ values for fruit stored at 0 or fruit color of four cultivars of red raspberry.

4.5C due to a slight increase in value at 16 days of storage (Table 1). Also. the change in $\mathrm{L}^{*}$ value with storage time differed at 0 and $4.5 \mathrm{C}$ due to samples being lighter at $4.5 \mathrm{C}$ after 8 days of storage (data not shown).

Rates of change of $\mathrm{L}^{*}, \mathrm{a}^{*}$, and $\mathrm{b}^{*}$ did not differ among cultivars when compared at 0 and 4.5C (data not shown), 20C (data not shown), and at all three storage temperatures (Table 3). This lack of cultivar differences for rate of color change indicates that raspberry cultivars with fruit lighter, redder, and less blue at harvest will maintain this status after several days in storage.

When fruit was stored at 0 or $4.5 \mathrm{C}$ for up to 16 days, rates of change for $\mathrm{L}^{*}, \mathrm{a}^{*}$, and $\mathrm{b}^{*}$ for all storage periods over all cultivars were the same regardless of temperature (data not shown). However, over all cultivars, rates of change of $\mathrm{L}^{*}, \mathrm{a}^{*}$, and $\mathrm{b}^{*}$ were greater at $20 \mathrm{C}$ than at 0 or $4.5 \mathrm{C}$ during the first 4 days, and rates of change between 4 and 8 days were the same at all temperatures (Table 3).

Previous storage studies found that anthocyanin content in raspberries stored up to 36 days was cultivar-dependent but that there was no interaction with storage time (Robbins and Sjulin, 1989). This result indicates that, although anthocyanin content increased with time, the rate of anthocyanin increase was the same for all cultivars. We have found here a high correlation of $\mathrm{L}^{*} \mathrm{a}^{*} \mathrm{~b}^{*}$ with anthocyanin content $(r=-0.73$. -0.80 , and -0.79 , respectively) and a similar cultivar response for color change. The rate of increase in $\mathrm{pH}$ value during storage was different among cultivars, while the rate of decrease in titratable acid was the same among cultivars in our previous study (Robbins and Sjulin, 1989). These conflicting findings in-

Table 3. Effect of cultivar and storage temperature on rate of color change of red raspberry fruit.

\begin{tabular}{|c|c|c|c|c|c|c|}
\hline \multirow[b]{4}{*}{ Variable } & \multicolumn{6}{|c|}{ Units of decrcasc in color coordinate value per day } \\
\hline & \multicolumn{2}{|c|}{$L^{*}$} & \multicolumn{2}{|c|}{$\mathrm{a}^{*}$} & \multicolumn{2}{|c|}{$b^{*}$} \\
\hline & \multicolumn{6}{|c|}{ Storage period (days) } \\
\hline & $0 \rightarrow 4$ & 48 & $0-4$ & 48 & $0-4$ & $4-8$ \\
\hline \multicolumn{7}{|l|}{$\overline{\text { Cultivar }[\mathrm{C}]}$} \\
\hline Chilcotin & 0.44 & 0.12 & 0.63 & 0.42 & 0.71 & 0.27 \\
\hline Meeker & 0.45 & 0.00 & 1.01 & 0.18 & 0.78 & 0.15 \\
\hline Nootka & 0.38 & 0.09 & 1.16 & 0.10 & 0.61 & 0.18 \\
\hline Willamette & 0.26 & 0.29 & 1.03 & 0.42 & 0.71 & 0.18 \\
\hline \multicolumn{7}{|c|}{$\begin{array}{l}\text { Storage temperature } \\
\left({ }^{\circ} \mathrm{C}\right)[\mathrm{T}]\end{array}$} \\
\hline 0 & 0.30 & 0.19 & 0.73 & 0.34 & 0.56 & 0.21 \\
\hline 4.5 & 0.14 & 0.08 & 0.50 & 0.33 & 0.45 & 0.19 \\
\hline 20 & 0.70 & 0.10 & 1.65 & 0.17 & 1.09 & 0.18 \\
\hline \multicolumn{7}{|l|}{ Significance } \\
\hline $\mathrm{C}$ & NS & NS & NS & NS & NS & NS \\
\hline$T$ & $\cdots$ & NS & $\cdots$ & vs & $\because$ & NS \\
\hline$T$ linear & $* *$ & NS & $*$ & NS & "• & NS \\
\hline$T$ rcsidual & $*$ & vs & $\cdots$ & vS & $\cdots$ & NS \\
\hline $\mathrm{C} \times \mathrm{T}$ & NS & iss & NS & NS & NS & NS \\
\hline
\end{tabular}

${ }_{\mathrm{NS}}, * *$ Nonsignificant or significant at $P=0.01$. dicate that amounts of anthocyanin may be more important in visible color change than shifts in the levels of acidity. Further studies would be needed to confirm this hypothesis.

In this study, relative differences between cultivars for color and rates of change were the same. Higher temperatures led to higher rates of change, especially during the first 4 days at 20C. This relationship indicates that, to screen raspberry clones for color changes and any possible differences in rates of change during storage. evaluation at harvest and after 4 days at $20 \mathrm{C}$ should provide information similar to storage for longer periods at 0 or 4.5C.

Storage of raspberry fruit at $0 \mathrm{C}$ is recommended for maximum storage life (Salunkhe and Desal, 1984). In this study, 0C had some practical advantage (higher $\mathrm{a}^{*}$ and $b^{*}$ values) for color maintenance compared to $4.5 \mathrm{C}$ for the relatively long storage period of 16 days. It is likely that, for shorter storage periods, 0C would also be preferred for preservation of other quality characteristics such as firmness and flavor components.

These data indicate that cultivars having lighter, redder fruit with little blue going into storage will result in lighter, redder, less blue fruit after storage. This being the case, two genotypes with similar $\mathrm{L}^{*}, \mathrm{a}^{*}, \mathrm{~b}^{*}$ readings at harvest should have similar readings after storage, since their rate of color change would be equal. Further studies are needed to confirm this hypothesis.

\section{Literature Cited}

Eagerman, B.A., F.M. Clydesdale, and F.J. Francis. 1973a. Comparison of color scales for dark colored beverages. J.. Food Sci. 38:1051-1055.

Eagerman, B.A., F.M. Clydesdale, and F.J. Francis. 1973b. Development of new transmission color scales for dark colored beveragcs. J.. Food Sci. 38:1056-1059.

Robbins. J.A. and T.M. Sjulin. 1989. Postharvest storage characteristics and respiration rates in five cultivars of red raspberry. HortScience 24:980-982.

Salunkhe, D.K. and B.B. Desal. 1984. Small fruits-berries. Postharvest biotechnology of fruits. vol. I. CRC, Boca Raton, Fla.

Sjulin, T.M. and J.A. Robbins. 1983. Shelf life studies of red raspberry varieties. Proc. 73rd Annu. Meeting Western Wash. Hort. Assn. p. 116-122.

Sjulin, T.M. and J.A. Robbins. 1987. Effects of maturity, harvest date and storage time on postharvest quality of red raspberry fruit. J. Amer. Soc. Hort. Sci. 112:481-487.

Terre, L.C. and B.H. Barritt. 1977. Quantitative evaluation of Rubus fruit anthocyanin pigments. J. Food Sci. 42:488-490.

Varseveld. G.W. and D.G. Richardson. 1980. Evaluation of storage and processing quality of mechanically and hand-harvested Rubus spp. fruit. Acta Hort. 112:265-272. 